\title{
Neutronic Comparison of New HSA Cobalt Capsule Design to Legacy HSA Cobalt Capsule Design
}

B. J. Gross

January 2018

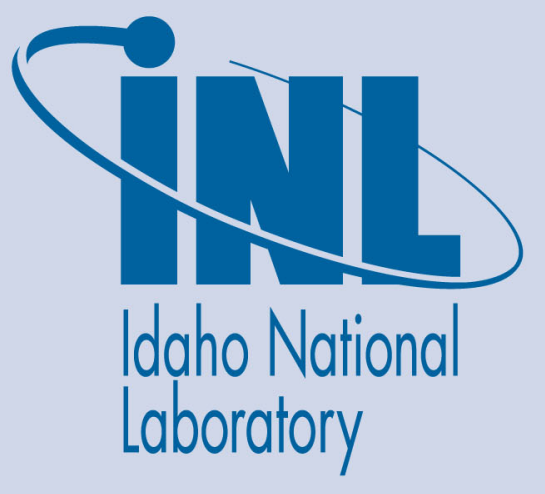

The INL is a U.S. Department of Energy National Laboratory operated by Battelle Energy Alliance 


\title{
Neutronic Comparison of New HSA Cobalt Capsule Design to Legacy HSA Cobalt Capsule Design
}

\author{
B. J. Gross
}

January 2018

Idaho National Laboratory Idaho Falls, Idaho 83415

http://www.inl.gov

Prepared for the

U.S. Department of Energy

Under DOE Idaho Operations Office

Contract DE-AC07-05ID14517 


\section{Neutronic Comparison of New HSA Cobalt Capsule Design to Legacy HSA Cobalt Capsule Design}

Performer:

Brian Gross

Technical Checker:

Jason Brookman

Date:

January 16, 2018

\section{$\underline{\text { Introduction/Scope }}$}

The high specific activity (HSA) cobalt capsule utilized for producing cobalt-60, referred to as the legacy HSA cobalt capsule (see Figure 1), was redesigned in 2014 [1][2].

Several of the newly designed HSA capsules (see Figure 2) have been irradiated in the Advanced Test Reactor (ATR) H-positions starting in ATR Cycle 157C to the present. Recent assay measurements have indicated significantly less cobalt-60 is being produced than was originally anticipated. The customer, International Isotopes Inc. (INIS), has requested an investigation into the cause of the reduced production.

Figure 1 Legacy HSA Cobalt Capsule Design

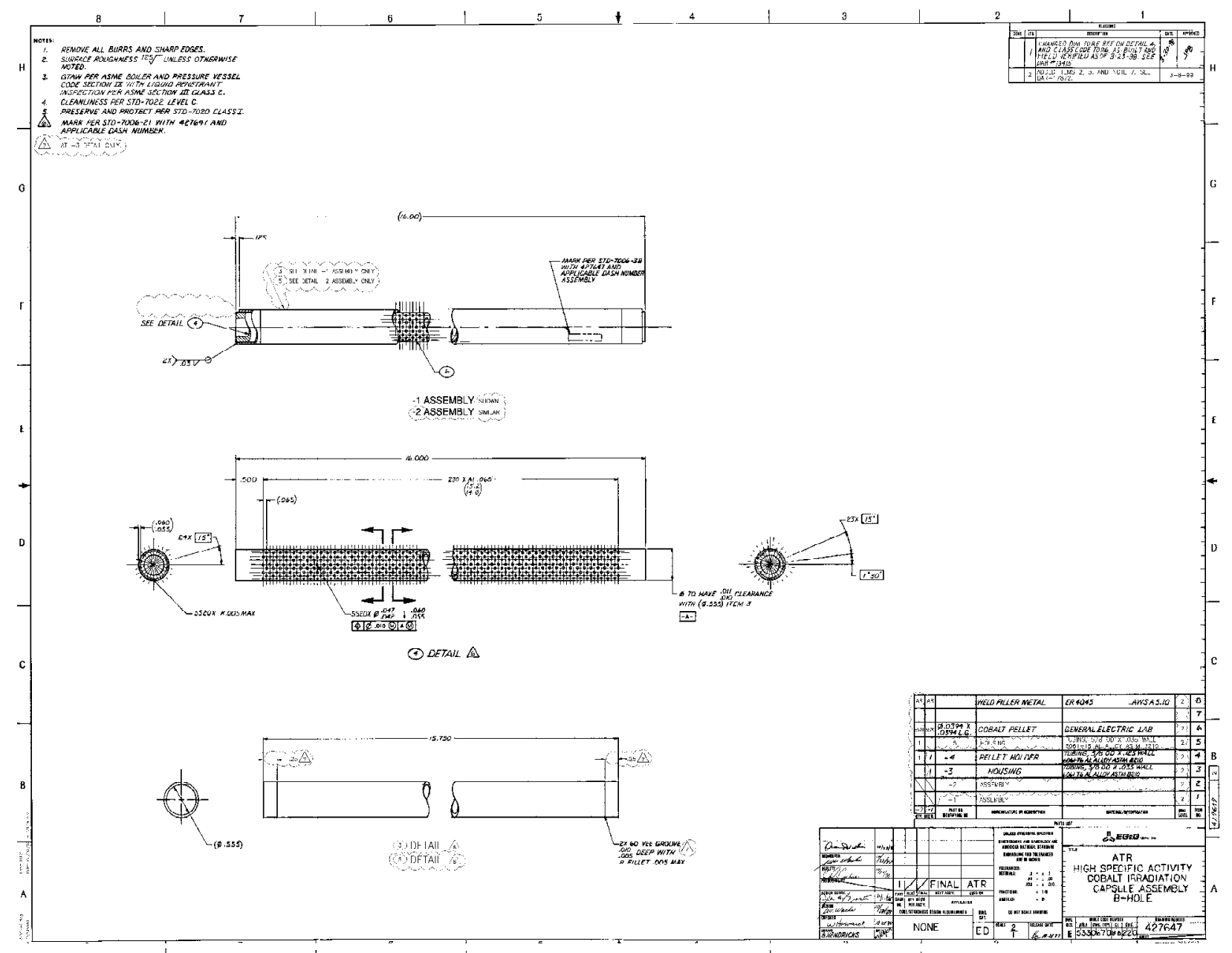




\section{Typical HSA Cobalt Capsule H Basket Experiment Assembly}

- Approximately 6,120 pellets per capsule ( $99 \%$ loaded)

- 3 capsules per basket

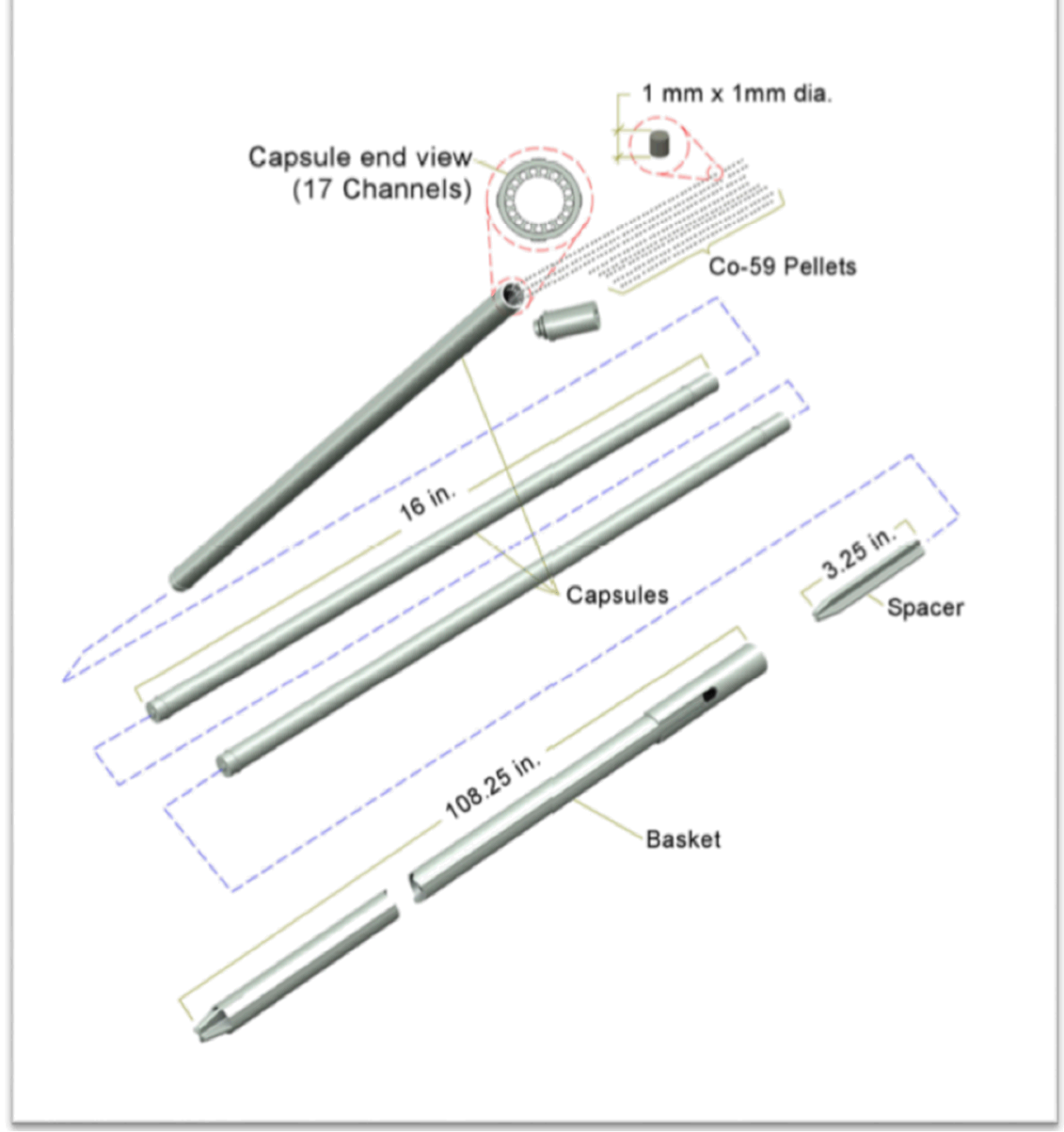

\section{Analysis}

One theory was the change in design may have negatively affected the effective neutron absorption cross section of cobalt- 59 that directly yields cobalt-60 ( $\mathrm{n}$, gamma). This analysis is a simple comparison of the cobalt- 59 target effective neutron absorption cross section (n, gamma) and the neutron flux averaged over all the cobalt-59 targets in each HSA cobalt capsule (top, middle, and bottom) placed in the H-5 position in ATR. Utilizing one of the existing MCNP models of ATR that was used for the as-run calculations and predictions documented in ECAR-3872 [3], the effective neutron absorption cross section and neutron flux averaged over each of the seventeen cobalt 59 pellet stacks (see Figure 3) was calculated for the top, middle, and bottom capsule in the $\mathrm{H}-5$ position in ATR. 
Figure 3 Horizontal Cross Section of MCNP model of H-5 Position in ATR

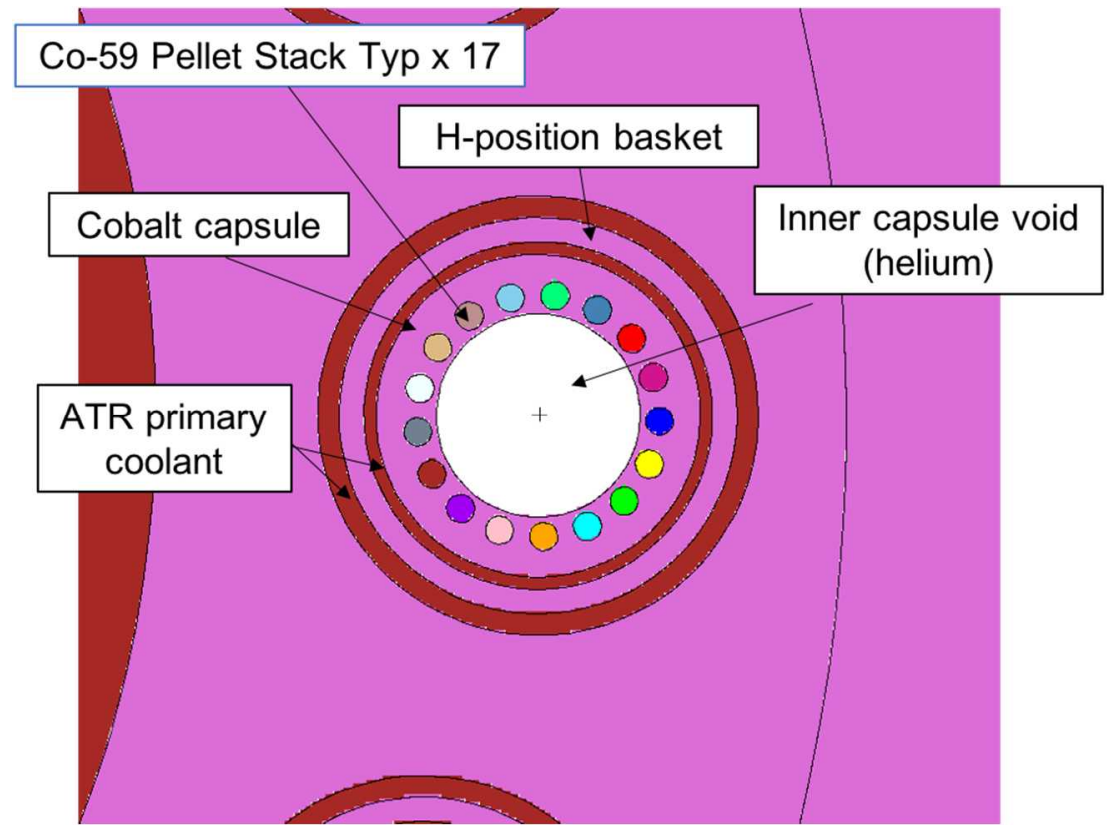

The three HSA capsules loaded in the $\mathrm{H}-5$ position were then swapped out with three legacy HSA capsules (see Figure 4) and the same calculation was performed.

Figure 4 Horizontal Cross Section of MCNP Model of Legacy HSA Cobalt in ATR H-5 Position

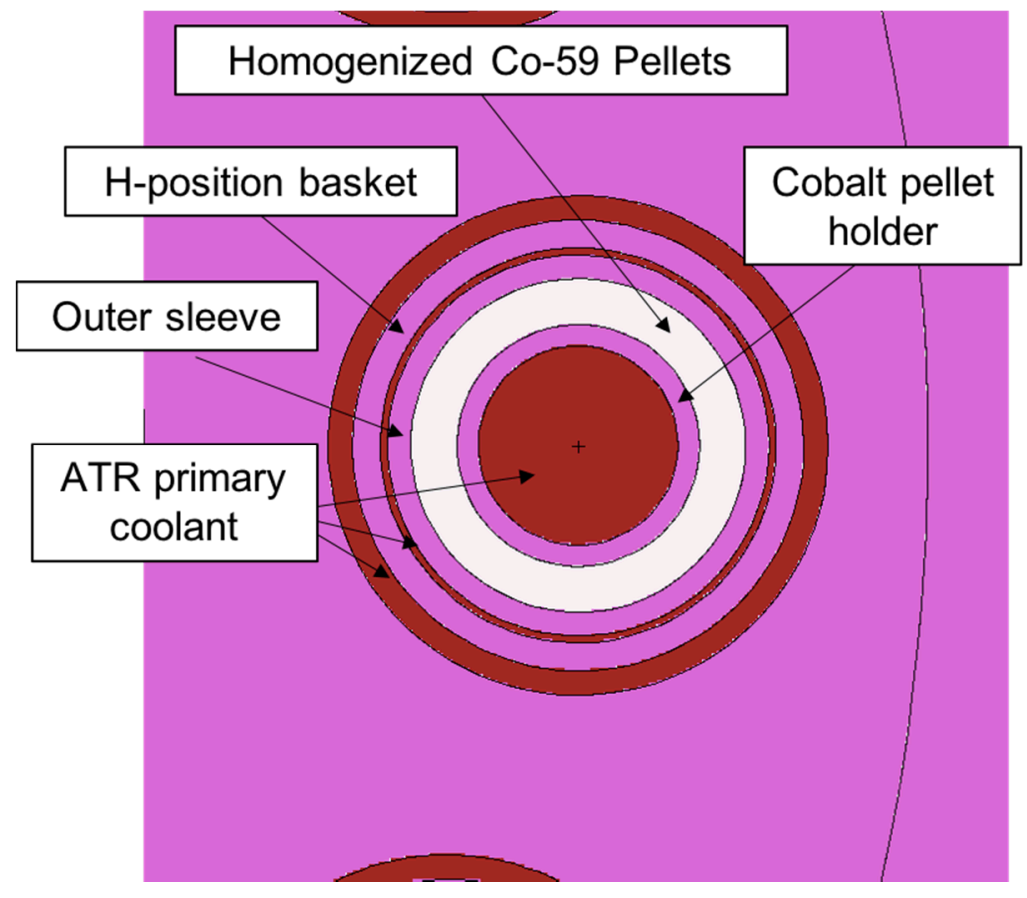




\section{Assumptions}

The following assumptions were used for this analysis:

1. The ATR lobe powers are 18.0, 17.0, 21.1, 20.1, and 25.0 MW (NW, NE, C, SW, SE).

2. The cobalt target material composition is pure cobalt-59.

3. The only change to the ATR reactor configuration is to the HSA capsules in position $\mathrm{H}-5$.

\section{Results/Conclusions}

Flux and effective neutron cross section results are shown in Table 1, Table 2, Table 3, Table 4, and Table 5. The effective neutron absorption cross section for the desired reaction ( $\mathrm{n}$,gamma) on the target material that directly produces Co-60 is slightly higher in the new design than the legacy design, and there is little statistical difference between the two target designs for the undesired reactions $(n, 2 n),(n, \alpha)$, and $(n, p)$.

Based on these results, neutronically, there does not appear to be a significant difference between the two capsule designs.

Table 1 Effective Cobalt-59 Neutron Cross Section for (n,gamma) Reaction

\begin{tabular}{|c|c|c|c|}
\hline \multirow{4}{*}{ Position } & \multirow{2}{*}{$\begin{array}{c}\text { Axial } \\
\text { Location }\end{array}$} & \multicolumn{2}{|c|}{$\begin{array}{c}\text { Cobalt-59 } \\
\text { (n,gamma) Cross } \\
\text { Section (b) }\end{array}$} \\
\cline { 3 - 4 } & & Legacy & New \\
\hline \multirow{3}{*}{ H-5 } & top & 4.40 & 4.78 \\
\cline { 2 - 4 } & middle & 4.48 & 4.87 \\
\cline { 2 - 4 } & bottom & 4.39 & 4.77 \\
\hline
\end{tabular}

Table 2 Effective Cobalt-59 Neutron Cross Section for $(n, 2 n)$ Reaction

\begin{tabular}{|c|c|c|c|}
\hline \multirow{4}{*}{ Position } & \multirow{2}{*}{$\begin{array}{c}\text { Axial } \\
\text { Location }\end{array}$} & \multicolumn{2}{|c|}{$\begin{array}{r}\text { Cobalt-59 (n,2n) Cross } \\
\text { Section (b) }\end{array}$} \\
\cline { 3 - 4 } & & Legacy & New \\
\hline \multirow{4}{*}{$\mathrm{H}-5$} & top & $2.44 \mathrm{E}-05$ & $2.66 \mathrm{E}-05$ \\
\cline { 2 - 4 } & middle & $2.77 \mathrm{E}-05$ & $2.80 \mathrm{E}-05$ \\
\cline { 2 - 4 } & bottom & $2.56 \mathrm{E}-05$ & $2.42 \mathrm{E}-05$ \\
\hline
\end{tabular}


Table 3 Effective Cobalt-59 Neutron Cross Section for (n,alpha) Reaction

\begin{tabular}{|c|c|c|c|}
\hline \multirow{4}{*}{ Position } & \multirow{2}{*}{$\begin{array}{c}\text { Axial } \\
\text { Location }\end{array}$} & \multicolumn{2}{|c|}{$\begin{array}{r}\text { Cobalt-59 }(\mathrm{n}, \mathrm{\alpha}) \text { Cross } \\
\text { Section }(\mathrm{b})\end{array}$} \\
\cline { 3 - 4 } & & Legacy & New \\
\hline \multirow{3}{*}{$\mathrm{H}-5$} & top & $2.63 \mathrm{E}-05$ & $2.69 \mathrm{E}-05$ \\
\cline { 2 - 4 } & middle & $2.61 \mathrm{E}-05$ & $2.66 \mathrm{E}-05$ \\
\cline { 2 - 4 } & bottom & $2.68 \mathrm{E}-05$ & $2.66 \mathrm{E}-05$ \\
\hline
\end{tabular}

Table 4 Effective Cobalt-59 Neutron Cross Section for $(n, p)$ Reaction

\begin{tabular}{|c|c|c|c|}
\hline \multirow{4}{*}{ Position } & \multirow{2}{*}{$\begin{array}{c}\text { Axial } \\
\text { Location }\end{array}$} & \multicolumn{2}{|c|}{$\begin{array}{r}\text { Cobalt-59 }(\mathrm{n}, \mathrm{p}) \text { Cross } \\
\text { Section (b) }\end{array}$} \\
\cline { 3 - 4 } & & Legacy & New \\
\hline \multirow{3}{*}{$\mathrm{H}-5$} & top & $2.66 \mathrm{E}-04$ & $2.70 \mathrm{E}-04$ \\
\cline { 2 - 4 } & middle & $2.64 \mathrm{E}-04$ & $2.68 \mathrm{E}-04$ \\
\cline { 2 - 4 } & bottom & $2.69 \mathrm{E}-04$ & $2.70 \mathrm{E}-04$ \\
\hline
\end{tabular}

Table 5 Average HSA Cobalt Target Neutron Flux Results

\begin{tabular}{|c|c|c|c|}
\hline \multirow{2}{*}{ Position } & \multirow{2}{*}{$\begin{array}{c}\text { Axial } \\
\text { Location }\end{array}$} & \multicolumn{2}{|c|}{$\begin{array}{c}\text { Neutron Flux } \\
\left(\mathrm{n} / \mathrm{cm}^{\wedge} 2^{*} \mathrm{~s}\right)\end{array}$} \\
\cline { 3 - 4 } & & Legacy & New \\
\hline \multirow{3}{*}{$\mathrm{H}-5$} & top & $4.75 \mathrm{E}+14$ & $4.90 \mathrm{E}+14$ \\
\cline { 2 - 4 } & middle & $8.01 \mathrm{E}+14$ & $8.25 \mathrm{E}+14$ \\
\cline { 2 - 4 } & bottom & $5.29 \mathrm{E}+14$ & $5.26 \mathrm{E}+14$ \\
\hline
\end{tabular}

\section{$\underline{\text { References }}$}

1. FOR-165, "DOE-SC Isotope Program Cobalt-60 Production Capsule Design", Rev. 0, March 6, 2014.

2. PLN-4723, "Experiment Analysis Plan for the HSA Cobalt-60 Isotope Production Program", Rev. 0, June 25, 2014.

3. ECAR-3872, "As-Run Physics Analysis of the HSA Cobalt Targets in the ATR H and Inner A-Positions for Cycles 157C through 161A and Projections through CIC", Rev. 0, February 2018. 